\title{
Instruções reais, advertências vice-reais. A escrita do governo ante as circunstâncias da Nova Espanha (século XVI)
}

\author{
Anderson Roberti dos Reis ${ }^{[1]}$
}

\begin{abstract}
Resumo
O presente artigo tem por objetivo analisar um conjunto documental referente ao governo da Nova Espanha: as instruções escritas em nome do rei e remetidas a seu alter ego na América; e as advertências, memórias e relações compostas pelos vice-reis ao final de seu mandato. Com isso, pretende-se examinar as conexões entre os dois tipos de documentos a fim de observar os temas privilegiados por ambos, bem como suas permanências e modificações durante as últimas quatro décadas do século XVI. Para tanto, tal conjunto será abordado sincrônica e diacronicamente de modo a tornar possível a análise sequencial, de um lado, de um mesmo tipo de fonte e, de outro, da relação entre o que a coroa orientava e o que vice-rei relatava ter feito. Parte-se da hipótese segundo a qual as circunstâncias vice-reais constituem elementos ativos na compreensão das permanências e mudanças nas estruturas daqueles documentos, particularmente das instruções reais. Palavras-chave: governo vice-real; Nova Espanha; instruções e advertências.

Royal instructions, viceregal notices. Writing the government in front of the New Spain's circumstances (16th century)
\end{abstract}

\begin{abstract}
This paper aims to analyze a set of documents related to the New Spain's government: the royal instructions sent to the viceroys; the notices, memories and reports written by the viceroys at the end of their mandate. Thus, this article intend to examine the connections between the two types of documents in order to scrutinize the most frequent topics in each one as well as how those themes remain or are changed in the instructions and memories during the last four decades of the sixteenth century. To this end, this article proposes an approach simultaneously diachronic and synchronic in order to make possible, on the one hand, the sequential analysis of the same type of sources and, on the other hand, the relationship between the royal instructions and the notices from the viceroy. This paper assumes that the viceregal circumstances constitute active elements to the comprehension of the permanence and change in the structures of those documents, particularly in the royal instructions.
\end{abstract}

Keywords: viceregal government; New Spain; instructions and reports.

Instructions royales, avertissements vice-royales. L'écriture du governement devant les circonstances de la Nouvelle Espagne (XVIe siècle)

\section{Résumé}

Cet article vise à analyser un ensemble de documents concernant au gouvernement de la Nouvelle Espagne : les instructions royales envoyées aux vice-rois en Amérique; et des avertissements, memoires et rapports écrits par les vice-rois au fin de leurs mandats. Ainsi, nous avons l'intention de examiner les liens entre les deux types de documents afin de observer les sujets privilégiés pour les deux, ainsi que les continuités et changements de ces sujets au cours des quatre dernières décennies du XVIe siècle. Pour ce faire, les sources seront examinées par approches synchroniques et diachroniques afin de permettre, d'une part, l'analyse séquentielle du même type de document et, d'autre part, la relation entre les instructions royales et ce que le vice-roi rapporté avoir fait. Cet article repose sur l'hypóthese que les circonstances du vice-royaume constituent les éléments actifs pour comprendre les continuités et changements dans les structures des ces documents, en particulier dans les instructions royales.

Mots-clés: Gouvernement du vice-royaume ; Nouvelle Espagne ; Instructions et Avertissements.

Instrucciones reales, advertencias virreinales. Escribir el gobierno frente a las circunstancias de la Nueva España (siglo XVI)

\section{Resumen}

Este artículo tiene como objetivo analizar un conjunto de documentos relacionados al gobierno de la Nueva España: las instrucciones reales enviadas a su alter ego en América; y las advertencias, memorias y relaciones escritas por los virreyes al final de sus mandatos. Así, nuestra intención es examinar las conexiones entre los dos tipos de documentos para observar los temas privilegiados en ambos, así como las continuidades y cambios de estos escritos durante las últimas cuatro décadas del siglo XVI. Con este fin, elegimos un abordaje al mismo tiempo sincrónico y diacrónico a fin de hacer posible, por un lado, el análisis secuencial de un mismo tipo de fuente y, por otro lado, la relación entre la orientación enviada por la Corona y lo que los virreyes informaban haber hecho. Este artículo tiene como hipótesis que las circunstancias virreinales constituyen elementos centrales a la comprensión de las continuidades y los cambios en las estructuras de esas fuentes, en particular de las instrucciones reales.

Palabras clave: gobierno virreinal; Nueva España; instrucciones y advertencias.

${ }^{[1]}$ Artigo recebido em 26 de abril de 2015 e aprovado para publicação em 15 de junho de 2015

${ }^{[2]}$ Professor do Departamento de História da Universidade Federal do Mato Grosso (UFMT) - Cuiabá - Brasil. E-mail: dosreiss@gmail.com 

possível que muitos historiadores alimentem, a cada visita a arquivos e bibliotecas, aquilo que Robert Darnton definiu como "o sonho de todo historiador": encontrar um conjunto documental inédito que parecia, em seu isolamento silencioso, apenas aguardá-lo para ganhar enfim a publicidade dada por sua leitura e interpretação (Pallares-Burke, 2000, p. 233-267). Em meio a estantes repletas de caixas e maços nos arquivos, ou nas dependências de uma igreja ou de uma antiga editora, muitos pesquisadores se movem atentos e cheios de expectativa em busca de evidências para completar lacunas na compreensão deste ou daquele período no passado. Para alguns processos históricos, examinados com grande frequência, a procura por (e o encontro de) indícios inéditos pode ser a única saída para o preenchimento de frestas ainda abertas. Talvez fosse esse o caso de Darnton, que dedicou uma vida à França do século XVIII, fartamente visitada por estudiosos do mundo todo, antes e depois de seu achado. Talvez seja esse o caso de tantos outros historiadores, cuja centralidade do objeto ou a escassez de fontes impulsionam a busca de novos documentos. No entanto, esse não parece ser o caso dos pesquisadores dedicados à história colonial americana que têm à disposição documentos que, se não são inéditos, estão longe de ser considerados "esgotados".

Entre as fontes disponíveis para o estudo da expansão da monarquia espanhola e de sua organização na América, uma tem despertado o interesse dos historiadores. Trata-se das instruções e relações de governo que acompanharam os vice-reis em seus mandatos. As primeiras, redigidas por conselheiros do monarca em nome de Sua Majestade, eram entregues ao vice-rei logo após sua nomeação. Ao partir da Espanha, o alter ego deveria estar ciente das questões com as quais lidaria e das expectativas da coroa quanto ao governo dos vice-reinos. Já as relações, memórias ou advertências cobriam a outra ponta desse processo: o registro escrito, ao final ou durante o mandato, do que ocorreu ou estava ocorrendo no vice-reinado e das matérias mais importantes às quais a coroa e o próximo governante teriam de prestar atenção. E nada deveria escapar do papel: tributos, evangelização, possíveis distúrbios, indígenas, espanhóis, vagabundos etc. Observadas em conjunto, instruções e relações sugeriam uma dinâmica retroalimentar, que será analisada adiante, na medida em que as informações prestadas pelo vice-rei deveriam colocar a coroa a par do estado de seus domínios e fundamentar, em consonância com as instruções reais, as ações de seu sucessor.

Embora não sejam as únicas a fornecer pistas acerca do sistema político espanhol na América, tais fontes, assim apresentadas, parecem abrir uma generosa janela à compreensão dos modos de governar. E de fato abrem. Às perguntas "o que a coroa espanhola priorizava e o que ela ordenava que se fizesse em determinados momentos?" e "o que os vice-reis afirmaram ter feito durante o período em que estiveram à frente da política americana?", as instruções e relações de governo podem dar boas respostas. Não por acaso, são conhecidas algumas edições desses documentos desde o final do século XVIII (Rodríguez, 
2011, p. 203), entre as quais cabe destacar a de Lewis Hanke nos anos 1970, de cujo esforço resultaram 12 volumes (cinco novo-hispânicos, sete peruanos) com papéis relativos aos vice-reinos americanos durante a dinastia Habsburgo, ${ }^{3}$ e, posteriormente, na década de 1990, os dois volumes assinados por Ernesto de la Torre Villar e Ramiro Navarro de Anda (1991), que priorizaram a Nova Espanha mas esticaram o arco temporal ao período bourbônico. Somem-se a esse material algumas edições mais antigas do século XIX ${ }^{4}$ e a publicação de instruções e relações avulsas, ${ }^{5}$ e será possível visualizar um amplo rol de documentos à disposição dos historiadores.

Se a reunião daquelas fontes em volumes publicados em série teve o mérito de franquear múltiplas possibilidades analíticas, sua edição evidenciou algo importante. As instruções escritas nos gabinetes do Conselho de Índias em nome do rei sofreram poucas modificações com o passar dos anos e com as sucessões vice-reais, principalmente durante os séculos XVI e XVII. Pode-se afirmar que, em linhas gerais, houve dois grandes modelos de instrução entre 1535 e 1700, quando reinaram os monarcas da Casa de Áustria. Um que é inaugurado com os dois primeiros vice-reis, Antonio de Mendoza (1535-1550) e Luis de Velasco (1550-1564), e se estende até 1596, quando os conselheiros orientam o conde de Monterrey (1595-1604), último alter ego nomeado por Felipe II (1556-1598), cujas instruções conformam o segundo modelo, que sofrerá durante o século XVII poucas alterações em sua organização geral. ${ }^{6}$ Enquanto as relações, memórias e advertências variavam em forma e conteúdo, década após década, as instruções mantiveram relativamente constantes, e por longos períodos, sua estrutura e o conjunto temático abordado.

É precisamente em torno dessa observação preliminar que se encontra a questão central deste artigo, que poderia ser assim enunciada: se se tratava de fontes retroalimentares e centrais ao bom governo dos vice-reinos americanos (e italianos), o que explica a repetição de instruções décadas a fio, quando a realidade grafada nas relações sugeria outras experiências? Outra formulação, agora pelo avesso, para esse mesmo problema consistiria em perguntar pelas razões que levaram à mudança nas instruções de 1596, reestruturando, assim, a sequência iniciada com os primeiros vice-reis novo-hispânicos. Os dois modos de indagar seguirão lado a lado neste estudo a fim de compreender a repetição das instruções reais em relação às advertências vice-reais e, posteriormente, as circunstâncias em que ocorreu a ruptura com aquele modelo. Metodologicamente, opta-se aqui pelo entrecruzamento de abordagens sincrônicas e diacrônicas das fontes. Isto é, ora se analisará o par "instrução e relação" de cada vice-rei, buscando aí os pontos de contato entre o que a coroa realçava

\footnotetext{
${ }^{3}$ Para a Nova Espanha, a referência é Hanke (1976-1978).

${ }^{4}$ Para os domínios peruanos, destaquem-se os volumes editados sob os auspícios do Ministério da Fazenda do Peru, em 1859, e que se encontram disponíveis on-line para consulta. Cf. Fuentes e Pontero (1859). Ver também Villena (1959).

${ }_{5}^{5}$ Para um exemplo, ver Conde e Sanchiz (1999, p. 137-153).

${ }^{6}$ Vale assinalar que, em duas instruções do século XVII (a Luis de Velasco, em 1607; eao duque de Albuquerque, em 1653), notam-se alterações que adicionam temas novos à espinha dorsal firmada na orientação dada ao conde de Monterrey, sem, contudo, rompê-la.
} 
e aquilo que o alter ego afirmava ser relevante, ora se examinará a sequência de relações e, depois, de instruções a fim de captar as mudanças e continuidades. Com isso, espera-se criar um quadro que permita formular uma hipótese que explique tanto a repetição quanto sua descontinuidade, especificamente no momento em que esta ocorreu. É necessário ressaltar que esta análise se circunscreve aos documentos relativos à Nova Espanha, com destaque àqueles elaborados na segunda metade do século XVI, durante o reinado de Felipe II.

\section{Uma dinâmica (supostamente) retroalimentar}

A comunicação incessante entre a coroa espanhola e seus domínios americanos era uma prática administrativa e uma obrigação legal. Antes mesmo de Felipe III (1598-1621) valer-se de uma série de cédulas reais para dar início à sistematização da circulação de informações nos primeiros decênios do século XVII, no que foi seguido por Felipe IV (1621-1665), os magistrados e conselheiros do rei inteiravam-se da situação vice-real por meio de um conjunto de relações, informes, advertências, cartas e correos que enlaçavam ininterruptamente as duas costas separadas pelo Atlântico. Encontra-se, por exemplo, nos apontamentos do primeiro vice-rei da Nova Espanha, Antonio de Mendoza, um indício seguro de que, conquanto não estivesse regulamentada de modo geral, a elaboração de uma relação de governo era exigência da coroa. Nesse documento, Antonio de Mendoza escreve à maneira de introdução: "Relación, apuntamientos y avisos que por mandado de S. M. di al Sr. Don Luis de Velasco, virrey y gobernador y capitán general de esta Nueva España." Outros vice-reis que governaram durante a segunda metade do século XVI deixaram pistas semelhantes - expressas nas relações escritas por Martín Enríquez (15681580) e pelo marquês de Villamanrique (1585-1590), para citar dois exemplos. ${ }^{8}$

$\mathrm{O}$ fato de os vice-reis de Felipe II terem sido obrigados a elaborar relações e advertências de governo não deve causar espanto, uma vez que o desejo desse monarca de ampliar o controle em terras americanas e de centralizar os mecanismos administrativos da coroa não constitui propriamente uma novidade. Talvez provoque maior surpresa a constatação de que não tenha sido o próprio Felipe II, mas seus sucessores, o principal responsável por regulamentar minuciosamente a elaboração daqueles documentos. ${ }^{9}$ Dispostas na Recopilación de las leyes de Indias encontram-se cédulas reais que estipulam

${ }^{7}$ Relación de Antonio de Mendoza a Luis de Velasco al término de su Gobierno. Sin fecha (c. 1550-1551). Extraído de Hanke (1976, p. 38).

${ }^{8}$ Martín Enríquez iniciou assim suas advertências: "Lo que S. M. me envía a mandar y V.S. me pide acerca de dejar algunos avisos de las cosas de esta tierra [...]." O marquês de Villamanrique optou por uma solução indireta e descritiva: "Memoria de las cosas que me ha parecido advertir al Sr. Virrey Don Luis de Velasco, conforme a lo que S. M. me manda por una real cédula suya acerca del estado en que están las de la tierra." Extraídos de Hanke (1976, p. 202 e 266)

${ }^{9}$ Embora Felipe II, na ordenanza 13 dada ao Conselho de Indias em 1571, tenha se referido à importância das cartas e relações escritas por vice-reis, oidores ou funcionários da Casa de Contratação, que "resultan las mayores noticias para matérias de gobernacion, á que se debe mucho atender, por lo que importa [...]". Essa ordenanza está disposta na Lei XXVIII, Título II, do Livro II da Recopilación de las Leyes de los Reinos de las Indias (5. ed. Madri: Boix, 1841 [1680]. t. I, p. 158). 
a obrigatoriedade da preparação das relações de governo, seu conteúdo (que precisaria contemplar as matérias de religião, governo, fazenda e guerra) e sua forma - que deveria primar por um estilo breve, claro, substancial, decente e sem generalidades. Se nas Leis 23 e 24, Título III, do Livro III da Recopilación, compostas com base em normas emitidas entre 1620 e 1628, legisla-se sobre a necessidade de o vice-rei colocar seu sucessor a par das matérias de governo, pessoalmente e/ou por escrito, ${ }^{10}$ a lei primeira, Título XIV, do Livro III define a condição que obriga o alter ego a prestar contas ao monarca do estado geral e particular de seu governo. ${ }^{11}$

\section{A comunicação incessante entre a coroa espanhola e seus domínios americanos era uma prática administrativa e uma obrigação legal}

Aliás, o texto dessa última lei exprime com precisão o anseio real e sugere a dinâmica retroalimentar que deveria pautar a elaboração das instruções e relações de governo. Firmada por Felipe III em 24 de abril de 1618 e coligida em 1680 na Recopilación, ela fixava uma obrigação que parecia ser rotineira nas práticas administrativas desde o final do século XVI (Rodríguez, 2011, p. 212). Lê-se:

Porque los vireyes tienen obligacion de darnos muy especial cuenta del estado general y particular de sus gobiernos como mas preeminentes ministros, para que tengamos individual noticia de las materias de su cargo y forma con que cumplen nuestras órdenes: Mandamos que ajustándose á las leyes que tratan de esta obligacion, y se dirigen á los presidentes, audiencias y prelados, nos avisen continuamente en primer lugar de todo lo que tocare á religion, culto divino y piedad; y en segundo, de lo tocante á gobierno militar, político y de hacienda [...]. ${ }^{12}$

O preceito se impõe com clareza. Cabia aos vice-reis informar continuamente sobre o estado de seu governo para que Sua Majestade e o Conselho de Índias soubessem a forma com que se cumpriam as ordens reais. Resta claro que essas ordens e os informes vice-reais ganhavam corpo em diferentes documentos (cédulas, ordenanzas, provisões e autos, de um lado; cartas e memoriais, de outro) ${ }^{13}$ nos quais se destacavam os aspectos mais particulares e circunstanciais, embora a visão de conjunto sobre o governo ficasse geralmente reservada às instruções reais e às relações e advertências vice-reais.

\footnotetext{
${ }^{10}$ Recopilación de las Leyes de los Reinos de las Indias. 5. ed. Madri: Boix, 1841 [1680]. t. II, p. 19-20.

${ }^{11}$ Ibidem, p. 66.

${ }^{12}$ Ibidem.

${ }^{13}$ Para uma apreciação do conjunto normativo indiano, ver Góngora (1951) e Anzoátegui (1992).
} 
Alguns estudiosos reconheceram valor nesse conjunto documental e não pouparam esforços para caracterizá-lo. Talvez motivados pela formulação do jurista madrilenho Juan de Solórzano y Pereyra, em sua Política indiana (1648), certos historiadores realçaram a função limitadora das instruções reais. Em meados do século XVII, ao sistematizar seus pressupostos sobre o governo na América, Solórzano assegurava que as instruções públicas ou secretas cumpriam a função de obrigar os vice-reis a observá-las, "en las quales, por distintos, y bien ordenados capitulos, se les advierte lo que han de hacer [...]" (Pereyra, 1776 [1648], p. 372). Logo, aqueles homens deveriam ler as instruções e observá-las, verbo cujo sentido comporta aqui a ação de guardar e cumprir exatamente o que se manda (da matriz latina de observare e servare). Nesse sentido, as instruções funcionavam como uma régua moral que delimitava a extensão do campo de ação vice-real. Encontram-se afinados a essa leitura, que parece ser predominante, estudos variados, como os de José Ignacio Rubio Mañé, Ernesto de la Torre Villar, Javier Sanchiz e José Ignacio Conde, Patricio Zamora Navia, Fernando Ciaramitaro e Christian Büschges, para citar apenas alguns autores. ${ }^{14}$ Em síntese e consoante a tal perspectiva, a instrução limitava e cingia a conduta do vice-rei, remarcando a autoridade da coroa na definição da política colonial.

De modo semelhante, há análises que jogam luz sobre a função orientadora das instruções ou sobre seu caráter oficial, o que não as opõem necessariamente ao papel "limitador" destacado anteriormente, mas de certa forma amortece o impacto de sua função. Tal apreciação pode ser lida, por exemplo, nos recentes textos assinados por Manfredi Merluzzi (2012) e em um artigo de 1989 de Manuel Rivero Rodríguez acerca dos vice-reinos italianos, no qual se distinguem naqueles documentos duas funções: "hasta finales del siglo XVI tuvieron una función indicativa más do que normativa, inicialmente consistieron en recomendaciones dadas para resolver problemas concretos y orientar la labor de gobierno" (Rodríguez, 1989, p. 198). Indicar, recomendar, orientar, transmitir diretrizes e linhas políticas: tais eram, partindo dessa perspectiva, as ações desempenhadas pelas instruções, que só a partir do século XVII teriam um caráter normativo.

Seja qual for a função principal desses documentos no século XVI, limitar o poder dos vice-reis ou orientá-los - ou uma provável combinação das duas coisas -, o fato é que eles parecem ocupar um lugar relevante na dinâmica de governo da monarquia espanhola na América. Alimentadas pelas relações, memórias, advertências e demais informes grafados pelos vice-reis, cuja consciência se encontrava obrigada pelo monarca, as instruções dariam a medida das ações do vicário real. Ocorre que a importância com a qual se recobre a existência e as funções das instruções reais, particularmente aquelas relativas à Nova Espanha, esbarra em uma constatação incômoda: seu conteúdo e sua forma são praticamente invariáveis na segunda metade do século XVI, afirmação

${ }_{14}$ Mañé (1985, p. 81-84); Villar e Anda (1991, p. XLXI); Conde e Sanchiz (1999, p. 137); Navia (2012, p. 203-205); Ciaramitaro (2008, p. 119); Büschges (2012). 
que vale especialmente para os documentos firmados no gabinete de Felipe II. Por outras palavras: de 1566 (quando o marquês de Falces embarcou rumo ao México) a 1596 (com a orientação a conde de Monterrey), os conselheiros reais alteraram significativamente as instruções em apenas uma ocasião, justamente esta última. Três décadas, seis vice-reis, cinco instruções, quatro relações de governo ou advertências e muitas mudanças na Nova Espanha. Somente na nomeação do sétimo homem para exercer a função de proreges é que se notam alterações na composição daquela que seria a sexta instrução despachada para o México durante o período de Felipe II. ${ }^{15}$

\section{Descompassos e permanências}

Não é necessária mais do que uma leitura do conjunto documental para captar essa especificidade. Optando-se inicialmente pela análise sincrônica, tomando as instruções e advertências relativas a um vice-rei como referenciais, ou pela abordagem diacrônica, espaçando as fontes em uma linha do tempo, o observador poderá notar, a despeito dos temas comuns à linguagem política daqueles homens, certo descompasso entre a permanência da orientação real e as particularidades das relações vice-reais entre 1566 e 1596. Embora a experiência constitua uma categoria importante na construção dos argumentos presentes em instruções e advertências - de fato, ela supõe a base da dinâmica retroalimentar sugerida na medida em que fundamentaria as decisões da coroa -, seu efeito parece amortecido quando se examinam conjuntamente os dois tipos de documentos.

Por um lado, as cinco instruções reais que conformam o modelo predominante durante o reinado de Felipe II organizam-se em 57 ou 58 capítulos que tratam, com diferenças pontuais no conteúdo (ou em seu estilo) e na referência nominal ao vice-rei anterior, dos seguintes temas: cuidado e conversão dos ameríndios (atuação dos cleros secular e regular); Fazenda Real (terras, culturas, trabalhos, impostos); obrigações administrativas e morais do vice-rei; e obras públicas e policía no vice-reino (segurança, povoação, costumes). Isso ocorre a despeito das diferentes mãos pelas quais passaram tais documentos, uma vez que tanto o corpo de conselheiros do monarca como os secretários do Conselho de Índias não permaneceram os mesmos nos quatro decênios finais do século XVI. ${ }^{16}$ Ao analisá-las em sequência, nota-se a repetição dos temas,

\footnotetext{
${ }^{15}$ Os vice-reis aos quais se referem os dados são: Marquês de Falces (1566-1567); Martín Enríquez (1568-1580); conde de La Coruña (1580-1583); Pedro Moya de Contreras (interino, 1584-1585); marquês de Villamanrique (1585-1590); Luis de Velasco (1590-1595); e conde de Monterrey (1595-1603). É importante destacar que o conde de La Coruña morreu durante seu mandato e não deixou relação de governo, ao passo que seu sucessor, porque interino, não recebeu instruções nem escreveu quaisquer memórias ou advertências.

${ }^{16}$ Com relação a essa matéria, cabe lembrar que ocuparam o posto de secretário do Conselho de Indias - que em algumas ocasiões, a depender da proximidade com o soberano, era também uma espécie de secretário real, além de responsável pelos documentos recebidos e enviados aos vice-reinos americanos com a firma do monarca - no período aqui destacado: Francisco de Eraso, que referendou as instruções dadas ao marquês de Falces e a Martín Enríquez; Antonio de Eraso, herdeiro da função de seu pai e que organizou os papéis dados ao conde de La Coruña e ao marquês de Villamanrique; e Juan de Ibarra, que cuidou das instruções passadas a Luis de Velasco e, em 1596, ao conde de Monterrey.
} 
distribuídos pelos mesmos tópicos, com quatro exceções relevantes: a exclusão de um item (sobre a produção de um corante) que constava da instrução recebida por Martín Enríquez e que desaparece nos documentos seguintes; a inclusão de uma importante orientação (item 38), a partir de 1580, a respeito do inconveniente provocado pelo casamento de filhos e filhas de funcionários das Reais Audiências em seus próprios distritos; o desdobramento de um tópico em dois na instrução recebida pelo marquês de Villamanrique; e a menção específica aos índios chichimecas no item 21 do documento dirigido a Luis de Velasco, el hijo, em 1589, no qual se orientava sobre a edificação de povoados para garantir a segurança e a ocupação da terra, " $y$ particularmente para estoruar las ymbasiones de los yndios chichimecas donde tanto daño resulta". ${ }^{17}$

Por outro lado, os relatos deixados pelos vice-reis variaram na forma e no conteúdo, a começar pelo memorial escrito pelo marquês de Falces três meses após tomar posse, cujo objetivo pareceu ser menos oferecer uma visão de conjunto sobre suas ações como vice-rei do que elaborar um diagnóstico da situação da Nova Espanha, especialmente em razão dos conflitos da coroa com alguns conquistadores, entre eles os herdeiros de Hernán Cortés. Ainda assim, Falces vale-se de um texto contínuo para destacar temas importantes ao governo vice-real, a exemplo da própria "rebelião de Martín Cortés", de suas relações com as demais autoridades civis, da situação e do ânimo dos religiosos, das tensões com pueblos de la frontera (chichimecas e guachachiles) ou das questões ligadas à Fazenda Real. Em meio a assuntos recorrentes, chama a atenção o destaque à norma que regulamentava os tecidos e tipos de vestidos apropriados para o México, realçando um aspecto pouco mencionado nas outras fontes. Norma essa, diga-se, que não foi aplicada pelo vice-rei para evitar descontentamentos. ${ }^{18}$

Curiosidades à parte, o documento enviado pelo marquês de Falces à Espanha distinguia-se daqueles escritos por seus sucessores em um aspecto fundamental: não tinha por finalidade primeira advertir seu substituto. Dirigido exclusivamente ao monarca, sua meta não consistia em apontar os melhores caminhos para o bom governo americano - conquanto oferecesse um bom panorama sobre temas cruciais ao vice-reino - , ao contrário do que se acha nos advertimientos compostos por Martín Enríquez, pelo marquês de Villamanrique e por Luís de Velasco. Diante da variedade de temas e das formas da escrita, a função de advertência, evidenciada pelo modo como o autor se dirige diretamente a seu sucessor, talvez seja o primeiro ponto de identidade entre tais papéis, juntamente com a abordagem de assuntos comuns ao ofício daqueles homens: trato com os indígenas; andamento das missões e das tensões entre as ordens religiosas e o clero secular; atenção à Fazenda Real; segurança, pacificação e povoamento do vice-reino.

\footnotetext{
${ }_{17}$ Instrvción de Sv Magestad tocante al govierno de Nveva España, 19 jul. 1589 apud Conde e Sanchiz (1999, p. 146).

${ }^{18}$ Memorial del marqués de Falces sobre las condiciones de México. In: Hanke (1976, p. 182).
} 
Embora tivessem propósitos e uma coluna temática semelhantes, as advertências vice-reais diferiram entre si em aspectos relevantes. Inicialmente, observam-se distinções formais, principalmente quanto ao estilo e ao tamanho da relação. Enquanto Enríquez e Velasco dividem seu texto em 20 e 21 itens, respectivamente, Villamanrique se estende por 34 tópicos, o que não deixa de ser eloquente, conforme se discutirá adiante. Também são distintos os temas com os quais se iniciam os relatos. Martín Enríquez considerou importante ressaltar a necessidade de harmonia entre vice-rei e Real Audiência para, em seguida, enfatizar o dever de cuidar dos indígenas e administrar as tensões clericais e civis. Villamanrique achou por bem dedicar quase toda a primeira metade de suas advertências aos cuidados com a Fazenda Real, destrinchando aspectos administrativos e fiscais, enquanto Velasco enfatizou nos tópicos iniciais as ações de defesa, povoamento e pacificação de indígenas em áreas periféricas do vice-reino.

\section{Cabia aos vice-reis informar continuamente sobre o estado de seu governo para que Sua Majestade e o Conselho de Índias soubessem a forma com que se cumpriam as ordens reais}

Além dessas diferenças, as três advertências apresentam particularidades que merecem ser sublinhadas. Martín Enríquez, por exemplo, abriu e fechou seu relato oferecendo um aconselhamento acerca do próprio ofício de vice-rei. $\mathrm{Na}$ abertura, alertou sobre a conformidade e a paz que devem selar as relações entre as autoridades americanas - "las cabezas de su gobierno" -, embora do vice-rei se espera que "ha de ser padre de todo". Nas folhas finais, Enríquez recomendou prudência a seu sucessor quando lidasse com "señores curiosos", que, interessados em distorcer os feitos dos vice-reis novo-hispânicos, acudiam aos governantes recém-chegados para lhes oferecer suas opiniões. ${ }^{19} \mathrm{O}$ recado de Enríquez parecia claro: além de ocupar-se com o governo em si, o vice-rei não deveria se esquecer de seu legado, da memória de seu mandato.

A Martín Enríquez soou igualmente conveniente o cuidado com possíveis rebeliões entre indígenas, negros e mestiços, motivo pelo qual sugeria a proibição do uso de armas e a restrição das montarias a cavalo para esses grupos — ainda que não fosse desejável deixar transparecer qualquer tipo de temor ou receio por parte das autoridades. A suspeita do vice-rei tinha lastro em uma percepção, há tempos enraizada nas relações de governo, sobre os vagabundos e seus vícios, entre os quais estavam os jogos de naipes, roubos e danos à Fazenda Real. O marquês de Villamanrique, a exemplo do que se lê nos documentos de seu sucessor, Luis de Velasco, el hijo, e nos papéis do primeiro

${ }^{19}$ Advertimientos de Martín Enríquez al conde de La Coruña, su sucesor. In: Hanke (1976, p. 202-203 e 212-213). 
vice-rei, Antonio de Mendoza, também notaria os hábitos "perniciosos" de negros e mulatos livres e desocupados. ${ }^{20}$ Porém, surgia no horizonte de preocupações de Villamanrique um problema que parecia superar em importância a vagabundagem de certos grupos pelas praças do vice-reino. Tratava-se da proibição de casamentos de familiares, quase sempre filhos e filhas, de funcionários da Real Audiência com habitantes do mesmo distrito sem a licença do rei - condição que havia sido normatizada na década de 1570, com a intenção de evitar favorecimentos por ocasião da administração da justiça por aquela instituição, e que já constava da instrução real dada ao conde de La Coruña em 1580, segundo se apontou anteriormente. Sinal de que tal matéria merecia destaque é o fato de Villamanrique ter dedicado quatro tópicos e algumas folhas de suas advertências para relatar casos em que se descumpriu a norma.

Compreende-se que as especificidades de cada relação de governo têm como referência as experiências e circunstâncias que marcaram os respectivos mandatos. Explicam-se assim, por exemplo, as razões que levaram Martín Enríquez a reafirmar a autoridade vice-real em uma década (1570) que, após as tensões criadas a partir das reivindicações de conquistadores e seus herdeiros, foi marcada pelos esforços da coroa espanhola para centralizar a administração de seus domínios americanos. Da mesma maneira, justifica-se a atenção dada por Luis de Velasco, nos anos 1590, aos projetos de povoamento e pacificação, uma vez que as expansões às regiões ao norte e ao noroeste do vice-reino, cada vez mais sistemáticas nos decênios finais do século XVI, topavam com grupos indígenas desconhecidos em situações que frequentemente terminaram em conflito. Assim, pode-se sustentar que as advertências respondiam, então, a dois importantes pontos de influxo: de um lado, às constantes instruções reais, que deveriam oferecer as diretrizes ao alter ego durante todo o tempo de seu governo; e, de outro, às circunstâncias efetivas de seu mandato, que se encarregariam de abrir espaço para as novidades e imprevistos. $\mathrm{O}$ vice-rei não poderia, portanto, negligenciar as instruções reais, mas também não era prudente ignorar as particularidades surgidas ao sabor das ocasiões.

O que se tem sugerido aqui é que, embora as relações e advertências vice-reais captem e expressem certas circunstâncias novo-hispânicas, as instruções reais permanecem quase inalteradas e muitas vezes indiferentes a tais especificidades, pelo menos até o último vice-rei empossado por Felipe II, o conde de Monterrey. Ainda que determinados temas e a própria linguagem das instruções repercutam nas advertências, estas vocalizam problemas concretos de governo para os quais parece haver alguma surdez. E não se trata de minudências ou casuísmos, mas de questões relevantes que, com o cotejo das fontes, saltam à vista. Talvez o primeiro exemplo seja o tema "guerra com os chichimecas", que atravessa as relações de Martín Enríquez (item 16), Villamanrique (item 20) e Velasco (item 1), mas que só é mencionado de modo superficial na instrução dada a este último vice-rei em uma frase que é acrescentada ao item 21 , mas que permanece isolada no conjunto das recomendações (" $y$

${ }^{20}$ Advertimientos generales que el marqués de Villamanrique dio a Luis de Velasco. In: Hanke (1976, p. 279). 
particularmente para estoruar las ymbasiones de los yndios chichimecas donde tanto daño resulta"), conforme se assinalou anteriormente. Aliás, o item 21 das instruções expressa bem o referido descompasso entre os dois tipos de documento, uma vez que por meio dele o monarca orienta o governante a cuidar da segurança e povoamento da Nova Espanha, relatando os lugares convenientes a edificação, e termina solicitando "y me avisaréis de lo que en ello hiciéreis". Pois, desde o memorial do marquês de Falces em meados dos anos 1560, e com repetições nas advertências dos demais vice-reis, a coroa tinha informações específicas a respeito dos "índios de fronteira”, mas insistia em uma recomendação genérica e formal.

\section{O vice-rei não poderia, portanto, negligenciar as instruções reais, mas também não era prudente ignorar as particularidades surgidas ao sabor das ocasiões.}

À semelhança da emergência dos "chichimecas" nas advertências contraposta à sua ausência nas instruções, outros assuntos importantes podem ser listados. É o caso, para citar um exemplo diferente, dos chamados "pleitistas", espanhóis ou mestiços que, passando-se por representantes dos indígenas, os incitavam a se levantar contra a ordem vice-real por meio de petições as mais variadas. Tanto Enríquez quanto Villamanrique dedicaram várias linhas ao tema, enfatizando os inconvenientes, danos e "contradicciones de las tierras que los virreyes hacen mercedes en este reino en nombre de S. M. [...]",21 além dos próprios roubos de que eram vítimas os pueblos representados pelos "pleitistas". ${ }^{22}$ Apesar das tintas carregadas com que são descritos esses grupos na sociedade novo-hispânica, as orientações reais não se ocuparam deles, preferindo a reprodução de instruções redigidas antes mesmo de Felipe II ocupar o trono espanhol. Outros elementos caros ao governo mexicano, segundo a perspectiva dos vice-reis, poderiam ser apresentados - questões específicas sobre o comércio com as Filipinas, o surgimento da Companhia de Jesus no tenso ambiente de disputas entre as ordens religiosas e o clero secular, os jogos de naipes etc. - sem que fossem contemplados pelos papéis firmados no Conselho de Índias.

Alguém poderia objetar que, conquanto não apareçam explicitamente nas instruções reais "públicas", é possível que tais questões tenham sido abordadas em cartas, cédulas ou mesmo nas orientações "secretas", considerando-se que a versão pública daqueles documentos não esgotava os meios de comunicação entre a monarquia e seus vice-reinos estrangeiros. Tal observação soa

${ }^{21}$ Advertimientos de Martín Enríquez al conde de La Coruña, su sucesor. In: Hanke (1976, p. 205).

${ }^{22}$ Advertimientos generales que el marqués de Villamanrique dio a Luis de Velasco. In: Hanke (1976, p. 275). 
plausível. Porém, a levar essa objeção ao limite, corre-se o risco de, tendo em mente a repetição do mesmo formato por três décadas, reduzir as instruções reais públicas a mera formalidade, a um protocolo que, fechado às experiências americanas, pouco pode dizer acerca das dinâmicas do governo vice-real.

O argumento que se defende aqui é um pouco diferente, pois caso contrário não se poderiam explicar com alguma racionalidade os esforços empregados por historiadores de primeira linha na edição dessas fontes, tampouco compreender os estudos a elas dedicados. É certa a suposição do caráter protocolar das instruções, como também parece correta a conclusão a respeito de sua "surdez" a algumas circunstâncias. Contudo, essas duas características gerais não interditam sua função que é compor o rol de textos orientadores e normativos emitidos pela coroa espanhola. Firmadas no início do mandato de cada vice-rei, elas não capturam todas as questões apontadas pelos diferentes agentes civis e religiosos, que em geral ficam reservadas às advertências e relações de governo vice-reais e às correspondências e normas com circulação contínua entre os dois lados do Atlântico. Embora houvesse a expectativa de uma dinâmica retroalimentar, fomentada pelas regras que inicialmente instituíram a existência desses documentos, às instruções reais ficaram reservadas as linhas gerais e mais amplas da política hispânica para seus domínios estrangeiros que não eram totalmente indiferentes ao andamento da administração vice-real. Elas não constituíam as instruções reais, mas apenas uma parte delas, aquela inicial, que, se não incorporava integralmente as experiências americanas representadas pelas penas dos vice-reis, também não as ignorava por completo. Para exemplificar o que poderia perturbar a quase imobilidade da forma e do conteúdo das instruções reais, convém analisar as alterações para então buscar suas possíveis razões.

\section{As mudanças}

A repetição de modelos e a pouca variação na redação das instruções reais durante décadas não são novidades entre os historiadores. Já se notou mais de uma vez tal característica, em circunstâncias e estudos distintos. Desde a obra pioneira de Helmut Koenigsberger sobre o governo de Felipe II na Sicília, cujo título em espanhol é bastante eloquente, La práctica del imperio, ${ }^{23}$ até análises mais recentes, como as de Manuel Rivero Rodríguez e Ernesto de la Torre Villar, ${ }^{24}$ sublinhou-se com razão a "igualdade substancial daqueles documentos", para retomar a expressão de Koenigsberger. Nesses estudos, interpretou-se o "discurso monocórdio" das instruções ora como fruto da necessidade da coroa de respeitar o status quo, atendo-se aos pactos constitucionais e evitando descontinuidades normativas (no caso de Rivero Rodríguez), ora como resultado das peculiaridades administrativas de Felipe II, que correspondiam

${ }^{23}$ Koenigsberger (1989, p. 189). Originalmente, essa pesquisa saiu em 1951 com o título The government of Sicily under Phillipe of Spain: a study in the practice of empire.

${ }^{24}$ Rodríguez (1989, p. 200-201); Rodríguez (2011, p. 213-214); Villar e Anda (1991, p. L-LI). 
a certa mentalidade (Torre Villar) que presidia as ações de governo em relação aos vice-reinados americanos.

Esses autores também esboçaram explicações para as alterações nas formas ou funções das instruções. Para o âmbito italiano, Rivero Rodríguez sustentou que a descontinuidade decorria de um deslocamento do caráter daqueles papéis, cujo propósito no final do século XVI deixou de ser "orientador ou informativo" para tornar-se "normativo". Tal câmbio estava ligado, segundo o autor, a uma redefinição do próprio poder vice-real na parte final do reinado de Felipe II (Rodríguez, 1989, p. 204-205). Por sua vez, Ernesto de la Torre Villar sugeriu que, no caso da Nova Espanha, ocorreu uma mudança de mentalidade verificada na modificação do foco das instruções, que evidenciavam como a administração decaía. Referindo-se às instruções secretas ao marquês de Montesclaros em 1603, ele afirmou que "el Consejo y sus escribientes, a partir de estas instrucciones, se volvieron ritualistas, se apegaron a un formulario que nada tenía que ver con las nobles proyecciones de los primeros años" (Villar e Anda, 1991, p. LI).

A reavaliação do lugar da autoridade vice-real, a alteração do caráter das instruções ou o câmbio de mentalidades na administração espanhola parecem elementos plausíveis e necessários à apreensão das razões que podem justificar as mudanças em uma fonte marcada pela continuidade. Eles não só parecem, mas de fato constituem fatores explicativos importantes. Todavia, partindo dessa base, pretende-se aqui sugerir uma hipótese que acrescenta outro componente capaz de elucidar as causas da alteração no modelo de instruções adotado pela monarquia espanhola na segunda metade do século XVI, e portanto de impactar os modos de pensar e organizar o governo dos vice-reinos americanos - particularmente no caso novo-hispânico, que é objeto desta análise. Trata-se, pois, da suposição segundo a qual as vicissitudes que marcaram o governo do marquês de Villamanrique (1585-1590), somadas ao desfecho que teve o processo político-administrativo a que ele foi submetido logo após seu mandato, ajudam a esclarecer a alteração das instruções reais recebidas em 1596 pelo conde de Monterrey, o último proreges nomeado por Felipe II. Ao sugerir essa hipótese, opta-se por uma explicação mais particular e menos geral - ainda que os elementos de conjunto não sejam dispensáveis -, vinculada diretamente às circunstâncias e ao andamento dos governos vice-reais. ${ }^{25}$ Antes de colocar à prova tal hipótese, convém apontar o que exatamente mudou nas últimas instruções firmadas por Felipe II.

Ao contrário de seus antecessores, o conde de Monterrey desembarcou no porto de San Juan de Ulúa sem trazer na bagagem as instruções públicas para o bom governo da Nova Espanha. Nomeado em maio de 1595, ele pisou em Veracruz em setembro, tomando posse efetiva em 5 de novembro do mesmo ano. Curiosamente, as instruções, que seriam acompanhadas de outros despachos

25 É importante destacar que tal premissa dialoga com um campo de estudos que, embora heterogêneo, se desdobra das clássicas interpretações de Victor Tau Anzoátegui e Mario Góngora acerca do casuísmo na política e no direito indianos até leituras mais recentes, a exemplo daquela proposta por Alejandro Cañeque para o caso mexicano (Cañeque, 2004). 
do Conselho de Índias, só foram firmadas meses mais tarde, em 20 de março de 1596, quase um ano após sua nomeação. Essa não seria a única novidade. Ao receber aqueles papéis, Monterrey tinha em mãos um documento aparentemente igual aos dos vice-reis anteriores: uma saudação inicial e orientações desmembradas em 57 itens escritos em nome do rei e referendados pelo secretário Juan de Ibarra. Tais semelhanças, entretanto, eram apenas aparentes.

Se o aspecto formal aproximava aquelas instruções das anteriores, não seria preciso mais do que uma leitura para constatar as diferenças. Caso tenha consultado os arquivos da secretaria do vice-reino a fim de tomar ciência das instruções recebidas por seus antecessores - conforme se supunha que fizesse -, é provável que o conde de Monterrey, assim que teve em mãos as orientações reais das quais era o destinatário, tenha percebido as disparidades na forma e no conteúdo. Dos 57 tópicos que lia em março de 1596, 30 replicavam quase integralmente itens das instruções precedentes (com pequenas mudanças na redação que não lhe alteravam o cerne); sete remetiam a tópicos conhecidos pelos demais vice-reis, porém com nova redação ou com modificações substanciais na orientação; e 20 eram novos - não porque sempre abordavam temas inéditos (apenas alguns eram), mas porque recomendavam ações distintas ou inexistentes nos documentos anteriores. A tomar como parâmetro a repetição monocórdica das instruções por três décadas, essa nova configuração representava uma ruptura e tanto.

Observadas em conjunto, as alterações geraram um novo rearranjo na disposição das matérias que deveriam ser apreciadas pelo vice-rei. Enquanto as instruções firmadas entre 1566 e 1589 privilegiaram inicialmente a cristianização e o cuidado com os indígenas (missões, trabalho excessivo, tributos injustos etc.), aos quais se dedicaram os 20 primeiros tópicos, para então abordar os assuntos da administração vice-real e os temas ligados à policía da Nova Espanha, as orientações recebidas por Monterrey foram dispostas conforme novas prioridades. Os primeiros 10 itens recomendavam, então, o controle vice-real das atividades eclesiásticas e a manutenção da paz e concórdia no reino a todo custo, deixando para o segundo bloco temático a cristianização e o cuidado com os nativos (tópicos 11 a 22), que era seguido pelos itens votados à prática administrativa e à policía do vice-reino, que encerravam a instrução. No primeiro caso, a prioridade inicial pairava sobre os nativos; no segundo, sobre as relações entre os diferentes grupos que integravam a sociedade novo-hispânica.

A mudança no foco inicial não resultava apenas do rearranjo temático, mas decorria principalmente das inclusões feitas na instrução de 1596. Dos 10 primeiros itens, apenas quatro deles remetiam ao que lá já constava, e somente um (item 3) não alterava o teor da orientação. Os demais ensejavam novidades. Em vez de enfatizar nas primeiras linhas a necessidade de cristianizar e prover o melhor para os indígenas (homens, mulheres e crianças) e para os mestiços, optava-se por sublinhar o imperativo do controle vice-real ante as muitas possibilidades de discórdia e desobediência: entre os cleros secular e 
regular, com a Inquisição, com os indígenas ao norte do México, de modo a guiar as ações do proreges e assegurar o "derecho de mi patronazgo real" e que "procurando todos un fin y ayundandoos para alcanzarle una jurisdición a la otra, resulten los buenos efectos que espero". ${ }^{26}$

Tanto o bloco temático inicial quanto a maioria dos outros acréscimos espalhados pelo restante do documento apresentam uma característica comum: parecem responder a demandas concretas do vice-reino - situação que se evidencia, por exemplo, no número de vezes em que circunstâncias do mandato de Luis de Velasco são citadas para justificar ou explicar melhor determinada orientação, alterando a monotonia da repetição retórica das instruções anteriores. Entre as demandas, algumas das quais presentes nas advertências e relações de governo escritas pelos vice-reis, observa-se a preocupação da coroa com: os conflitos clericais e a reafirmação do patronato real, cujo impulso havia sido dado em 1574 com as Ordenanzas que lembravam às fileiras eclesiásticas os direitos da monarquia; ${ }^{27}$ as consequências das novas descobertas e expedições sistemáticas ao norte e noroeste do vice-reino, que acabavam em conflitos com diversos grupos indígenas em razão da política de redução, e especialmente com os chichimecas; ${ }^{28}$ a segurança do reino diante de instabilidades internas e ataques estrangeiros, principalmente de piratas, que agiram na costa novo-hispânica na década de 1580 com uma frequência maior do que o monarca poderia admitir; ${ }^{29}$ a manutenção da moralidade pública e da policía no vice-reino por meio do estrito cuidado com os vagabundos, os casamentos de parentes de oficiais da coroa em seus distritos ou com a presença de pessoas sem a licença real na Nova Espanha. ${ }^{30}$

Sob muitos aspectos, as instruções remetidas a Monterrey pareciam, portanto, mais sensíveis à conjuntura americana e menos surdas às experiências registradas nos papéis que circulavam entre os dois continentes, notadamente nas relações de governo enviadas por Enríquez, Villamanrique e Velasco. Diante disso, convém perguntar: por que em 1596 a rígida estrutura das instruções, que resistira à novidade por três décadas, foi parcialmente alterada? Defende-se aqui, conforme se afirmou anteriormente, que uma resposta plausível pode ser encontrada nas circunstâncias novo-hispânicas, especialmente nos episódios que marcaram o governo do marquês de Villamanrique.

\section{O ponto de virada}

Villamanrique tinha sido sábio, honesto e humano; célere ao cumprir seus deveres com o povo e leal a seu rei. Mas os piratas tinham chegado e capturaram o galeão, uma epidemia havia levado muitas pessoas a chorar, os terremotos assustavam-nas e o vice-rei não deixaria o ouvidor se casar. Que a filha

${ }^{26}$ Instrucción al conde de Monterrey. In: Hanke (1977, p. 129-130)

${ }^{27}$ Itens 1 a 10

28 Itens 2, 17, 23, 44, 47, 53.

29 Itens 2, 50, 54, 56.

30 Itens 13, 33, 45, 55, 56. 
única do vice-rei devia morrer, trazendo ao coração do pai mais tristeza do que ao contrário toda a Nova Espanha junta podia fazer, não era nada para eles. Os memoriais e relatórios desfavoráveis tiveram seu efeito sobre o monarca, que temia sobretudo uma repetição das dificuldades de Guadalajara, e então Villamanrique foi removido do cargo. Luis de Velasco, filho do ex-vice-rei de mesmo nome, foi nomeado para seu lugar, e Diego Romano, bispo de Tlaxcala, encarregado da residencia do vice-rei deposto. Esta última nomeação foi desastrosa para Villamanrique. O bispo Romano era um inimigo intransigente que havia esperado muito tempo por essa oportunidade. Ele convidou todos a apresentarem acusações, não importando sua trivialidade; ele as tornaria suficientemente relevantes. Especialmente os pedidos de dinheiro foram permitidos. O prelado se saiu bem em todas essas operações. Um servo fiel do rei foi humilhado, sua paz de espírito, destruída, seu orgulho, quebrado, e sua família, reduzida à pobreza. Romano estava feliz. Diferentemente de sua grande entrada no México foi a partida de Villamanrique; a primeira foi um triunfo; esta última, um funeral. Com sua aflita marquesa, e levando consigo os restos mortais de sua filha, o vice-rei partia de uma terra onde não havia encontrado nada além da desgraça e tristeza (Bancroft, 1883, p. 755-756; paráfrase e tradução nossas).

Foi assim que o historiador norte-americano Hubert H. Bancroft sintetizou, no último quarto do século XIX, o governo do marquês de Villamanrique. Além de tomar de assalto a atenção do leitor, o tom dramático emprestado à narrativa faz do mandato de Villamanrique uma vítima do infortúnio. O governante virtuoso tinha sucumbido a circunstâncias que lhe haviam interditado a boa sorte. Tal interpretação, de certo modo herdeira da versão do cronista franciscano Juan de Torquemada em sua Monarquía indiana (1615), ${ }^{31}$ não fez escola entre alguns historiadores do século XX, que optaram por juízos mais severos ao caracterizar o mandato daquele vice-rei como uma tirania, um período de censura e de escândalos (Mañé, 1983, p. 130-131); um fracasso completo (Israel, 2005, p. 29), decorrente das ações de um homem "terco, firme e inflexible" que não soubera conciliar o cumprimento da vontade real com os interesses locais. ${ }^{32}$ Talvez tenha sido o mexicano Ernesto de la Torre Villar, em 1991, o historiador a caracterizar o governo de Villamanrique de modo mais brando, ao afirmar que ele foi "un virrey juicioso y bien intencionado. Gobernó con honestidad y acrecentó el envío de grandes riquezas a España lo que despertó la ambición de los corsarios, apareciendo los piratas ingleses Cavendish en California y Drake en el Pacífico [...]".33

As diferentes análises historiográficas, se não são o objeto principal deste artigo, sugerem algo que parece consensual: o mandato de Villamanrique havia sido, como nenhum outro até então, marcado por tensões e conflitos do início

\footnotetext{
${ }^{31}$ Onde se lê que o governo de Villamanrique havia começado bem, porque ele era homem de bons princípios, sábio, sagaz e prudente, mas "luego se fueron ofreciendo negocios que lo fueron malquistando" (Torquemada, s.d., p. 418).

${ }^{32}$ Hanke (1976, p. 251-252). Richard Greenleaf (1968, p. 119-135) propõe algo parecido ao considerar Villamanrique um vice-rei severo empenhado em fazer cumprir as letras da lei.

${ }^{3}$ Villar e Anda (1991, p. 209). Para um apanhado mais amplo da historiografia a respeito de Villamanrique, ver Treviño (2000, p. 95-96)
} 
ao fim - não por acaso, o vice-rei fora removido de seu ofício. Podem-se listar os principais contratempos: 1) as disputas jurisdicionais com Pedro Moya de Contreras, arcebispo e visitador à época, mas antes de tudo um homem poderoso, que tinha estado à frente das principais instituições novo-hispânicas desde os anos 1570 (Inquisição, arcebispado, vice-reino); 2) os múltiplos conflitos que também eram jurisdicionais - com a Audiência de Guadalajara: ora em razão da guerra e pacificação dos índios chichimecas, uma vez que as matérias de guerra cabiam ao vice-rei, mas aqueles nativos se localizavam majoritariamente no distrito da Audiência, ora por causa da sigilosa administração da justiça naquele distrito, da qual o vice-rei pouco sabia ou tomava parte, ora resultantes das rusgas com os ouvidores, cujas práticas matrimoniais (casamentos de seus parentes no mesmo distrito, sem licença real) desrespeitavam as ordens reais; 3 ) as contendas com as ordens religiosas, e também com o clero secular, decorrentes da crescente secularização e controle das atividades missionárias desde a reafirmação do Real Patronato em 1574; 4) os problemas com a Inquisição por causa do controle vice-real sobre a circulação da correspondência daquele tribunal; 5) as ameaças de piratas e corsários à segurança do vice-reino e às finanças reais.

\section{As instruções remetidas a Monterrey pareciam mais sensíveis à conjuntura americana e menos surdas às experiências registradas nos papéis que circulavam entre os dois continentes}

Longe de querer resumir quatro anos de governo, essa lista enfatiza certos aspectos que fizeram do mandato de Villamanrique uma infeliz sequência de conflitos e desacertos. Por si só, ela seria suficiente para chamar a atenção da coroa espanhola e apoiar o argumento de que a passagem daquele vice-rei pela Nova Espanha constituiu um ponto de virada na composição das estratégias e das instruções de governo. Para tanto, basta observar o eixo temático que é inserido e/ou enfatizado nos documentos enviados ao conde de Monterrey em 1596 - já que Luis de Velasco, que sucedeu Villamanrique na Nova Espanha, recebeu suas instruções em 1589 (que ainda repetiam a estrutura das anteriores), antes de Felipe II e seus conselheiros conhecerem mais detalhes e o desfecho de todas as desordens. Não por coincidência, conforme se assinalou anteriormente, as novidades de 1596 insistem na paz e na conformidade entre os diferentes corpos e instituições (destacando, inclusive, as ordens religiosas, o clero secular e a Inquisição), na cooperação entre as jurisdições, no povoamento e na pacificação dos chichimecas, na segurança interna e externa do vice-reino e na obediência a certas normas, a exemplo das restrições matrimoniais aludidas. Enfim, as instruções pareciam espelhar, ao menos parcialmente, 
demandas circunstanciais da Nova Espanha, o que fundamentaria a hipótese que aqui se tem proposto.

No entanto, além dos próprios eventos em si, há outro dado que colaborou para romper o tom monocórdio das instruções ao mesmo tempo que arruinava a carreira de Villamanrique. Tratava-se dos memoriais, cartas e relatos produzidos por seus opositores durante e depois do mandato, responsáveis por elaborar a trama que acabou por fixar uma memória bastante desfavorável ao vice-rei e, em certo sentido, à própria situação política da Nova Espanha. As reclamações do cabildo catedralicio de Guadalajara durante as campanhas de pacificação entre os chichimecas; as acusações de favorecimento por ocasião da nomeação de Diego de Velasco, cunhado de Villamanrique, como capitão da guerra chichimeca (Schäfer, 2003; Treviño, 2000, p. 104); os cargos (faltas que se imputavam a oficiais da coroa) recolhidos durante a visita do bispo de Tlaxcala (e inimigo direto do vice-rei) Diego Romano e listados, entre 1592 e 1593, em longos documentos (Hanke, 1977, p. 9-75).

Tudo isso bastava para criar uma imagem desfavorável do vice-rei e de seu governo. Porém, outro golpe, bastante decisivo, tinha partido de onde Villamanrique não esperava: da pena de seu sucessor, que também era primo de sua esposa, Luis de Velasco. Às queixas e cargos que seriam levados à ciência do monarca, Velasco acrescentou uma "análise do memorial" de Villamanrique, escrita em 1590, na qual fazia considerações e críticas às ações de seu antecessor (Hanke, 1977, p. 89-99). Com essa prática pouco usual até então, levada adiante por um homem que gozava de grande consideração por parte da coroa, ampliava-se a lista dos "contras" na guerra de versões, embora o marquês tenha arriscado vários lances ao remeter memoriais ao Conselho de Índias nos anos 1590 a fim de se defender e recuperar seus bens e seu prestígio. Tais lances não surtiram efeito imediato. Villamanrique perdeu seu patrimônio e foi condenado ao desterro, penas que foram revogadas ainda no século XVII, nos primeiros anos do reinado de Felipe III. Antes de ver seu processo totalmente concluído, o ex-vice-rei morreu em 1604.

\section{Considerações finais}

Em setembro de 1580, às vésperas de partir da Nova Espanha rumo ao Peru, onde serviria novamente como vice-rei, Martín Enríquez encerrou os conselhos a seu sucessor com uma advertência intrigante, quando não metafísica. Afetando certa sabedoria impaciente, concluía assim suas anotações acerca da situação do vice-reino: "eu poderia dizer muitas outras coisas aqui, mas o tempo há de lhes ser o autor, e as ocasiões hão de trazê-las à tona”. As precisas sugestões caligrafadas nas páginas anteriores tornavam-se relativas diante daquelas palavras derradeiras. Rebeliões iminentes, impostos, comércio, grãos, armas: tudo isso era importante, mas havia ainda a expectativa com relação àquilo que o tempo mostraria conforme as ocasiões. Por meio da pluma de 
Enríquez, seu sucessor teria valiosas informações, embora algo lhe estivesse momentaneamente interditado: o conselho dado pelo tempo e pela experiência.

Nas linhas seguintes, percebe-se que a menção ao tempo não era fortuita. Ao complementar a ponderação, Martín Enríquez recomenda ao futuro vicerei que, se ele achasse alguma coisa relativa ao governo e à boa ordem fora de seu lugar, ou se muitos señores curiosos quisessem assim fazê-lo acreditar, considerasse que aquilo que "ahora se mira con ojos de nuevo, le parecerá lo que es andado el tiempo". Era preciso ser prudente e não dar crédito a tudo o que se dizia, "porque si en mil cosas que se les ofrecen se les hubiese de dar, todo lo que hicieron mis antecesores y lo que yo he hecho irá a su parecer errado, y lo mismo será después de V.S. y los demás" (Hanke, 1976, p. 212-213). Completo, o conselho revestia-se outra vez de concretude. O tempo deixava a dimensão metafísica e retornava à prática da política vice-real. A advertência era direta: ouça esses senhores, mas creia em poucos; caminhe devagar nos negócios até tê-los entendido. E, antes de avaliar as ações de seu antecessor com base nas opiniões, deixe o tempo passar, até que ele mostre como são as coisas na Nova Espanha. Preocupava a Martín Enríquez não apenas o aconselhamento para o bom governo, mas igualmente o legado de suas ações. A recomendação que serviu de epílogo às demais advertências era valiosa e acenava para um elemento importante na dinâmica institucional da monarquia espanhola: a disputa em torno da memória relativa às ações dos governantes.

As palavras de Martín Enríquez ganham sentido após a análise do desfecho do governo do marquês de Villamanrique. Que os diferentes conflitos, cuja confluência era notável e levou alguns a creditá-los aos infortúnios, minaram o mandato do vice-rei não há dúvidas. Villamanrique, no entanto, não era o primeiro e nem seria o último proreges a enfrentar dificuldades, embora se devam ressaltar a quantidade e as circunstâncias desses problemas. Talvez o singular nesse caso seja a memória criada por meio dos diferentes documentos que faziam circular as queixas e denúncias contra o vice-rei, fixando a imagem do mau governante que havia colocado a Nova Espanha à beira de uma guerra civil, a "guerrilha de Guadalajara", conforme a expressão consagrada por cronistas ainda no século XVII, a exemplo dos franciscanos Juan de Torquemada e Antonio Tello. ${ }^{34}$ Se é assim, então se podem compreender e explicar não apenas as vicissitudes do mandato de Villamanrique e de seu legado, mas também as alterações na estrutura das instruções reais, motivadas pelas circunstâncias novo-hispânicas, incluindo, portanto, como elemento ativo da dinâmica política espanhola, a dimensão vice-real.

${ }^{34}$ Embora não seja objeto de análise deste artigo, vale enfatizar que, além das instruções e relações de governo, outros dois documentos tinham importância significativa na produção da memória sobre o legado dos vice-reis (e dos altos funcionários de modo geral): os juicios de visitas, produzidos durante a passagem de um visitador por determinada região administrativa, o que poderia ocorrer a qualquer momento da gestão para apurar denúncias de delitos ou de abuso de poder por parte do governante; e os juicios de residencia, elaborados ao final do mandato a fim de recolher em um memorial os cargos contra o oficial, com base no qual o Conselho de Índias produziria uma sentença. 


\section{Referências bibliográficas}

ANZOÁTEGUI, Victor Tau. La ley en América Hispana: del descubrimiento a la emancipación. Buenos Aires: Academia Nacional de la Historia, 1992.

BANCROFT, Hubert H. The works of Hubert Howe Bancroft, v. X. History of Mexico, v. II 15211600. São Francisco: A. L. Bancroft \& Company Publishers, 1883.

BÜSCHGES, Christian. La corte virreinal como espacio político: el gobierno de los virreyes de la América hispánica entre monarquías, élites locales y casa nobiliária. In: CAÑEQUE, Alejandro. The king's living image: the culture and politics of viceregal power in Colonial Mexico. Nova York: Routledge, 2004.

CARDIM, Pedro; PALOS, Joan-Lluis (Ed.). El mundo de los virreyes en las monarquías de España y Portugal. Madri: Iberoamericana; Frankfurt: Vervuert, 2012.

CIARAMITARO, Fernando. El virrey y su gobierno en Nueva España y Sicilia: analogías y diferencias entre periferias del imperio hispânico. Estudios de Historia Novohispana, México, DF, v. 39, p. 119, jul./dez. 2008.

CONDE, José Ignacio; SANCHIZ, Javier. Las instrucciones reales al primer gobierno de don Luis de Velasco. Estudios de Historia Novohispana, México, DF, n. 20, p. 137-153, 1999.

FUENTES, Manuel Atanasio; PONTERO, Ambrosio Cerdan de Landa Simon. Memorias de los vireyes que han gobernado el Perú, durante el tiempo del coloniaje español. Lima: Librería Central de Felipe Bailly, 1859.

GÓNGORA, Mario. El Estado en el derecho indiano: época de fundación. 1492-1570. Santiago: Instituto de Investigaciones Histórico-Culturales, 1951.

GREENLEAF, Richard. The little war of Guadalajara. 1587-1590. New Mexico Historical Review, Albuquerque, v. 43, p. 119-135, 1968.

HANKE, Lewis. Los virreyes españoles en America durante la Casa de Austria (México). Madri: Atlas, 1976. v. I.

. Los virreyes españoles en America durante la Casa de Austria (México). Madri: Atlas, 1977. v. II.

ISRAEL, Jonathan I. Razas, clases sociales y vida política en el México colonial, 1610-1670. 4. reimp. México, DF: FCE, 2005 [1. ed. em inglês, 1975].

KOENIGSBERGER, Helmut G. La práctica del império. Madri: Alianza, 1989.

MAÑÉ, José Ignacio Rubio. El virreinato I: orígenes y jurisdicciones, y dinámica social de los virreyes. México, DF: FCE, 1983 [1. ed., 1955].

. El virreinato I: orígenes y jurisdicciones, y dinámica social de los virreyes. 2. ed. México DF: FCE, 1985 [1. ed., 1955].

MEMORIAL del marqués de Falces sobre las condiciones de México. In: HANKE, Lewis. Los virreyes españoles en America durante la Casa de Austria (México). Madri: Atlas, 1976. v. I, p. 182. MERLUZZI, Manfredi. Los virreyes y el gobierno de las Indias: las instrucciones al primer virrey de Nueva España (siglo XVI). In: CARDIM, Pedro; PALOS, Joan-Lluis (Ed.). El mundo de los virreyes en las monarquías de España y Portugal. Madri: Iberoamericana; Frankfurt: Vervuert, 2012. NAVIA, Patricio Zamora. Reyes y virreyes de la monarquía hispana a la luz de las significaciones políticas del siglo XVII y de la historiografia. Revista de Humanidades, Santiago, n. 25, p. 203-205, 2012.

PALLARES-BURKE, Maria Lúcia G. As muitas faces da história: nove entrevistas. São Paulo: Unesp, 2000.

PEREYRA, Juan de Solórzano y. Política indiana. Madri: Imprenta Real de la Gazeta, 1776 [1648]. RODRÍGUEZ, Manuel Rivero. Doctrina y práctica política en la monarquía hispana: las instrucciones dadas a los virreyes y gobernadores de Italia en los siglos XVI y XVII. Investigaciones Históricas, Valladolid, n. 9, 1989.

. La edad de oro de los virreyes: el virreinato en la monarquía hispánica durante los siglos XVI y XVII. Madri: Akal, 2011. 
SCHÄFER, Ernesto. El Consejo Real y Supremo de las Indias: su historia, organización y labor administrativa hasta la terminación de la Casa de Austria. Madri: Marcial Pons Ediciones de Historia, 2003. v. 2.

TORQUEMADA, Juan de. Monarquía indiana. México, DF: Unam, s.d. v. II.

TREVIÑO, Rigoberto Gerardo Ortiz. Nueva Galicia y Quito: la insubordinación de dos audiencias insubordinadas (1548-1680). 2000. p. 95-96. Disponível em: <http://www.larramendi.es/ i18n/consulta/registro.cmd?id=1123>. Acesso em: 22 mar. 2013.

VILLAR, Ernesto de la Torre; ANDA, Ramiro Navarro de. Instrucciones y memorias de los virreyes novohispanos. México, DF: Porrúa, 1991. v. I.

VILLENA, Guillermo Lohmann. Las relaciones de los virreyes del Perú. Sevilla: Escuela de Estudios Hispano-Americanos, 1959. 